\title{
DOES TRANEXAMIC ACID STABILISED FIBRIN SUPPORT THE OSTEOGENIC DIFFERENTIATION OF HUMAN PERIOSTEUM DERIVED CELLS?
}

\author{
J. Demol ${ }^{1,3}$, J. Eyckmans ${ }^{2,3}$, S.J. Roberts ${ }^{2,3}$, F.P. Luyten ${ }^{2,3}$ and H. Van Oosterwyck ${ }^{1,3, *}$ \\ ${ }^{1}$ Division of Biomechanics and Engineering Design, \\ ${ }^{2}$ Laboratory for Skeletal Development and Joint Disorders, \\ ${ }^{3}$ Prometheus, Division of Skeletal Tissue Engineering Leuven, K.U. Leuven, Leuven, Belgium
}

\begin{abstract}
Fibrin sealants have long been used as carrier for osteogenic cells in bone regeneration. However, it has not been demonstrated whether fibrin's role is limited to delivering cells to the bone defect or whether fibrin enhances osteogenesis. This study investigated fibrin's influence on the behaviour of human periosteum-derived cells (hPDCs) when cultured in vitro under osteogenic conditions in twodimensional (fibrin substrate) and three-dimensional (fibrin carrier) environments. Tranexamic acid (TEA) was used to reduce fibrin degradation after investigating its effect on hPDCs in monolayer culture on plastic. TEA did not affect proliferation nor calcium deposition of hPDCs under these conditions. Expression profiles of specific osteogenic markers were also maintained within the presence of TEA, apart from reduced alkaline phosphatase (ALP) expression (day 14). Compared to plastic, proliferation was upregulated on 2D fibrin substrates with a $220 \%$ higher DNA content by day 21 . Gene expression was also altered, with significantly $(p<0.05)$ decreased Runx2 (day 7) and ALP (day 14) expression and increased collagen I expression (day 14 and 21). In contrast to plastic, mineralisation was absent on fibrin substrates. Inside fibrin carriers, hPDCs were uniformly distributed. Moderate cell growth and reduced osteogenic marker expression was observed inside fibrin carriers. After 2 weeks, increased cell death was present in the carrier's centre. In conclusion, fibrin negatively influences osteogenic differentiation, compared to culture plastic, but enhanced proliferation (at least in 2D cultures) for hPDCs cultured in osteogenic conditions. TEA maintained the integrity of fibrin-based constructs, with minor effects on the osteogenic differentiation of hPDCs.
\end{abstract}

Keywords: Bone, cell-material interactions, fibrin, hydrogels, human periosteum derived cells, in vitro, tissue engineering.

\author{
*Address for correspondence: \\ Hans Van Oosterwyck \\ K.U.Leuven - Division of Biomechanics and Engineering \\ Design \\ Celestijnenlaan 300C, PB 2419 \\ 3001 Leuven, Belgium
}

Telephone Number: +32 16327067

FAX Number: +32 16327994

E-mail: Hans.VanOosterwyck@mech.kuleuven.be

\section{Introduction}

Fibrin is a natural polymer that is formed during blood clotting from its precursor protein fibrinogen. The conversion of fibrinogen to fibrin is triggered by thrombin (Blomback, 1996). In fibrin sealants, this coagulation process has been engineered into an adhesive system that is widely used in many surgical fields to promote haemostasis, sealing and tissue bonding. Commercial fibrin sealant kits contain highly purified and virally inactivated human fibrinogen and human thrombin (Jackson, 2001). Fibrin is a non-cytotoxic, fully resorbable, bioactive matrix with multiple interaction sites for cells and other proteins (Mosesson et al., 2001). As a result, fibrin is a relevant biological matrix that has been explored extensively in multiple preclinical and clinical studies as a carrier material for osteogenic cells to form osteogenic composites for bone and joint surgery. However, not all studies obtained the same result. Some studies attributed excellent osteogenic and osteoinductive properties to fibrin (Kania et al., 1998; Tholpady et al., 1999; Isogai et al., 2000; Perka et al., 2000; Abiraman et al., 2002; Kalia et al., 2009), while others reported nonsignificant positive and negative results (Jarzem et al., 1996; Brittberg et al., 1997; Carmagnola et al., 2000; Cunin et al., 2000).

In vivo studies have investigated the association of fibrin sealant with osteogenic cells as a bioactive coating on orthopaedic implants or as a bone substitute for large bone defects. Kalia et al. sprayed autologous bone marrow-derived stromal cells in fibrin sealant onto the surface of cementless acetabular components of total hip prostheses to increase the integration of the coated implant into the bone (Kalia et al., 2009). They found increased bone area around the implants, improved bone-implant contact, and reduced fibrous tissue thickness when implants were treated with cells and fibrin as compared to implants treated with fibrin alone. In a critical-sized defect model in rats, Tholpady et al. investigated bone healing in an engineered construct containing fibrin sealant with or without osteoprogenitor cells (Tholpady et al., 1999). Fibrin sealant alone significantly improved bone healing when compared to control groups (no implant). Bone healing was further improved when the fibrin sealant was combined with osteoprogenitor cells. Perka et al. also demonstrated a positive effect on bone formation with constructs combining periosteal cells and fibrin sealant in bone defects in a rabbit model (Perka $e t$ al., 2000). However, no signs of efficient bone healing were detected in the constructs composed of fibrin sealant alone. In concordance, a study by Isogai et al. compared fibrin sealant containing cultured periosteal cells with 


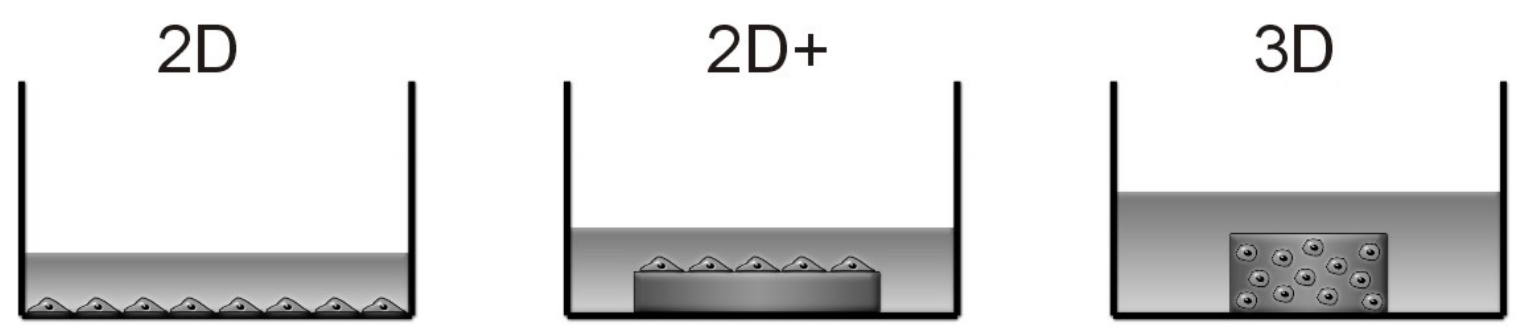

Fig. 1. Schematic representation of the different experimental set-ups used to study the influence of fibrin and tranexamic acid on human periosteum derived cells during two- and three-dimensional culture.

fibrin sealant alone in heterotopic sites in nude mice (Isogai et al., 2000). After 12 weeks, newly formed bone structures were present in all cell-fibrin constructs, but no bone formation was identified within fibrin alone. Additionally, fibrin's potential as a component of bone substitutes has also been investigated by combining ceramic biomaterials (without cells) with fibrin sealant (reviewed by Le Guehennec et al., 2004). For example, Abiraman et al. and Kania et al. reported that the addition of fibrin to ceramic biomaterials promoted new bone formation as compared to the ceramics alone (Kania et al., 1998; Abiraman et al., 2002). Conversely, Carmagnola et al. and Cunin et al. showed that the presence of fibrin impaired bone healing (Carmagnola et al., 2000; Cunin et al., 2000).

Because of the various outcomes of in vivo studies, it still remains unclear whether fibrin's role in bone regeneration is limited to the delivery of progenitor cells to the defect site or whether fibrin has osteoconductive or even osteoinductive properties that enhance new bone formation. Some signs indicative of the latter can be found in the in vitro studies by Bensaid et al. and Catelas et al. (Bensaid et al., 2003; Catelas et al., 2006). They reported respectively that mesenchymal stem cells (MSCs) were able to express alkaline phosphatase (a bone marker) and to differentiate into an osteogenic lineage when cultured three-dimensionally (3D) inside fibrin sealants (Tisseel). However, until now the ability of MSCs to undergo full osteogenic differentiation when combined with a fibrin sealant has not yet been demonstrated in vitro.

For the in vitro culture of fibrin-based constructs, care must be taken that the gradual degradation of the fibrin is controlled to prevent excessive loss of shape and biomechanical properties. Different strategies have been described that aim at guiding the in vitro degradation of fibrin. Eyrich et al. developed fibrin hydrogels for cartilage engineering that remained stable for 5 weeks in vitro by modifying the $\mathrm{pH}$ and the concentrations of fibrinogen and calcium ions (Eyrich et al., 2007). Fibrinolytic inhibition has also been tested as a means of stabilising fibrin. This can be achieved with different antifibrinolytic agents such as aprotinin (Meinhart et al., 1999; Lee et al., 2005; Huang et al., 2007), ع-aminocaproic acid (Huang et al., 2007; Kupcsik et al., 2009) or tranexamic acid (TEA) (Meinhart et al., 1999; Cholewinski et al., 2009). Meinhart et al. indicated that tranexamic acid inhibited the fibrinolytic activity of chondrocytes effectively without influencing the viability of the cells or their ability to produce specific matrix components (Meinhart et al.,
1999). Recently, Cholewinski et al. came to a similar conclusion using tranexamic acid to stabilise fibrin-based constructs for cardiovascular tissue engineering (Cholewinski et al., 2009).

For bone regeneration, the main cell sources for MSCs are bone marrow (Friedenstein et al., 1966), periosteum (Nakahara et al., 1990) and adipose tissue (Zuk et al., 2001). Cells isolated from the periosteum form a clinically relevant cell population for skeletal engineering because of the critical role of the periosteum in postnatal bone healing. In addition, human periosteum-derived cells (hPDCs) have shown, both in vitro and in vivo, to possess a subpopulation of osteoprogenitor cells (De Bari et al., 2006; Eyckmans and Luyten, 2006). Their potential for regenerating bone appears to be at least comparable with that of bone marrow-derived MSCs and superior to that of adipose-derived progenitor cells ( $\mathrm{Ng}$ et al., 2005; Arnsdorf et al., 2009).

The main goal of this study is to investigate the in vitro viability, proliferation and differentiation of hPDCs when associated with a fibrin sealant and cultured under osteogenic conditions. Cell-fibrin combinations can be applied either as a bioactive coating for orthopaedic implants or as an engineered bone substitute for nonhealing bone defects. In the case of the former, cells will perceive their environment as more two-dimensional (2D), while in the case of an engineered bone construct, the fibrin carrier will form a real $3 \mathrm{D}$ environment to the cells. As a result, the dimensionality of the hPDC-seeded fibrin constructs should be considered when evaluating the influence of fibrin on the behaviour of the hPDCs. Therefore, this study first investigated the cell-material interaction in a $2 \mathrm{D}$-like environment by studying the behaviour of hPDCs cultured on fibrin substrates (denominated 2D+) and comparing it to culture plastic (2D). Secondly, cells were encapsulated in fibrin and 3D cultured to evaluate fibrin as a carrier for hPDCs (Fig. 1). Finally, tranexamic acid (TEA) was investigated as a potential medium supplement to help maintain the integrity of fibrin-based constructs in vitro without being cytotoxic and hindering proliferation and osteogenic differentiation of hPDCs. However, TEA's influence on cell behaviour in a $3 \mathrm{D}$ culture environment is always coupled to the effect degradation may have on encapsulated cells. Therefore, this question was subdivided into two parts, where the effect of TEA on proliferation and differentiation was studied by means of 2D culture experiments, and its effect on fibrin degradation by means of $3 \mathrm{D}$ experiments. 


\section{Materials and Methods}

\section{Cell isolation and culture}

Cells were isolated from periosteal biopsies of human donors as previously described (Eyckmans et al., 2010). Briefly, periosteal biopsies $\left(10 \times 5 \mathrm{~mm}^{2}\right)$ were harvested during distraction osteogenesis surgery or within $12 \mathrm{~h}$ post mortem. A periosteal lifter was used to strip the periosteum of the tibia. The biopsies were transported in growth medium (GM, high-glucose Dulbecco's modified Eagle's medium (DMEM, Invitrogen, Merelbeke, Belgium) containing $10 \%$ foetal bovine serum (FBS, Gibco, Invitrogen) and antibiotic-antimycotic solution (Invitrogen)). The periosteal specimens were finely minced and digested overnight at $37^{\circ} \mathrm{C}$ in $0.2 \%$ type IV collagenase (Invitrogen) in growth medium. Subsequently, periosteal cells were collected by centrifugation and plated in a T25 culture flask in growth medium. After 5 days, non-adherent cells were removed by changing the medium.

Cells from five donors of various ages $(3,7,23,29$, and 34 years) and sexes ( 2 male and 3 female donors) were pooled to focus on the average rather than donor-specific interactions (by reducing the genetic variability) of this cell source with the biomaterial. Pooled cells were expanded in T175 culture flasks (Greiner, Wemmel, Belgium) in growth medium. Upon confluence, hPDCs were released with a tryspin-like enzyme treatment (TrypLE Express, Invitrogen) and replated at a seeding density of 6000 cells $/ \mathrm{cm}^{2}$. For cryopreservation, hPDCs were suspended in DMEM with $20 \%$ FBS and $10 \%$ dimethylsulfoxide (DMSO, Sigma, Bornem, Belgium) and stored in liquid nitrogen. All experiments were performed with expanded cell populations of passage 7 or 8 .

Osteogenic medium was used to induce the differentiation of hPDCs into the osteogenic lineage. This osteogenic medium (OM) consisted of StemPro MSC serum-free medium (Invitrogen) supplemented with 100 $\mathrm{nM}$ dexamethasone, $10 \mathrm{mM} \beta$-glycerophosphate and 0.05 $\mathrm{mM}$ L-ascorbic acid (all from Sigma). When indicated, $0.5 \mathrm{mg} / \mathrm{mL}$ tranexamic acid (Exacyl, Eumedica, Belgium) was added to the medium to delay fibrin degradation (OM+TEA).

\section{D culture}

The influence of TEA on the osteogenic differentiation of hPDCs was investigated using monolayer cultures with or without TEA being present in the OM. Therefore hPDCs were plated at a density of 3000 cells $/ \mathrm{cm}^{2}$ in 12 -well plates (NUNC, Langenselbold, Germany). The following day, medium was replaced with inductive medium (with or without TEA) to start the treatment. This time point was denoted as day 0. During the 3 weeks of in vitro culture, the medium was replaced twice a week.

\section{D+ culture}

Fibrin sealant (Tisseel VH S/D, supplied by Baxter Innovations $\mathrm{GmbH}$, Austria) was used to prepare substrates to culture the hPDCs on. The fibrinogen and thrombin components of the fibrin sealant were diluted using the dilution buffers provided by Baxter. These buffers are formulated such that only the active ingredients are diluted, while the concentration of all other are kept constant. Equal amounts of both components were mixed by vortexing, resulting in a final concentration of $33 \mathrm{mg} / \mathrm{mL}$ of fibrinogen and $1 \mathrm{U} / \mathrm{mL}$ of thrombin. Of this mixture, $250 \mu \mathrm{L}$ was transferred into a polypropylene ring (inner diameter of $15 \mathrm{~mm}$ ), which was placed in the well of a 12-well plate (Greiner) as a mould for preparing the fibrin substrate. The 12-well plates had a hydrophobic surface to prevent cell attachment to the plastic (as used for suspension cultures). After $1 \mathrm{~h}$ of polymerisation at $37^{\circ} \mathrm{C}$, cells suspended in $0.5 \mathrm{~mL}$ of OM+TEA were seeded on the substrate at 3000 cells $/ \mathrm{cm}^{2}$, which is the same seeding density as in $2 \mathrm{D} .5 \mathrm{~h}$ later, the plastic ring was removed and an additional $1 \mathrm{~mL}$ of OM+TEA was added carefully to make sure that no cells were washed away from the substrate's surface. This was also confirmed by visual inspection using an inverted microscope. During 2D+ culture only medium supplemented with TEA was used to avoid cell attachment to plastic after the fibrin had degraded. Cell-seeded substrates were cultured for 3 weeks and medium was replaced twice a week.

\section{D culture}

Cells were encapsulated in fibrin sealant (Tisseel VH S/ D) to create cell-seeded carriers for 3D culture. Cylindrical hydrogels ( $\varnothing 8 \mathrm{~mm}$ x $4 \mathrm{~mm}$ ) were prepared by resuspending the hPDCs in the thrombin component. The cell-thrombin solution was added to an equal volume of fibrinogen component, vortexed briefly and pipetted into a custom made stainless steel mould. Subsequently the mould was placed at $37^{\circ} \mathrm{C}$ for $1 \mathrm{~h}$. After removing the hydrogels from the mould, they were rinsed with $2 \mathrm{~mL}$ phosphate buffered saline (PBS, Lonza, Verviers, Belgium) and placed in 12-well plates in $2 \mathrm{~mL}$ medium. Wells were coated with agarose to prevent cell attachment. The hydrogels had a final composition of $33 \mathrm{mg} / \mathrm{mL}$ fibrinogen and $1 \mathrm{U} / \mathrm{mL}$ thrombin with a cell density of 1 million cells/ $\mathrm{mL}$. The hydrogel constructs were cultured in OM or OM+TEA for 3 weeks. The medium was changed twice a week.

\section{Histology}

Samples of 2D+ and 3D culture were analysed histologically at day 0,14 and 21. Each sample was washed with $2 \mathrm{~mL}$ of PBS, fixed overnight in $4 \%$ formaldehyde and paraffin embedded. Serial cross-sections of $6 \mu \mathrm{m}$ thick were prepared and stained with haematoxylin and eosin (H\&E).

\section{Calcium deposition}

The presence of calcium deposits was assayed by alizarin red S staining (McGee-Russell, 1958). In 2D cultures, the medium was removed first. Then, the samples were rinsed with $2 \mathrm{~mL}$ of PBS and fixed in $4 \%$ formaldehyde. Subsequently, the well surface was covered with an aqueous solution of $2 \%$ alizarin red S (Sigma) of which the $\mathrm{pH}$ was adjusted to 4.2 with ammonium hydroxide. 
After 3 min, cultures were washed thoroughly with distilled water. The amount of deposited calcium was quantified by releasing the calcium-bound alizarin red $\mathrm{S}$ into solution with $10 \%$ cetylpyridinium chloride for $90 \mathrm{~min}$ at room temperature. The absorbance of the solubilised alizarin red $\mathrm{S}$ was measured at $570 \mathrm{~nm}$ and normalised to the total DNA content. The calcium deposition in monolayer cultures with $\mathrm{OM}$ and $\mathrm{OM}+\mathrm{TEA}$ were compared to 2 negative controls: cells cultured in growth medium (GM) and in StemPro MSC serum-free medium without osteogenic supplements (SFM).

In $2 \mathrm{D}+$ and $3 \mathrm{D}$ cultures, histological sections were deparaffinised and covered with the alizarin red $\mathrm{S}$ staining solution for $3 \mathrm{~min}$. The stained samples were washed with distilled water, air dried and then visualised under a microscope (Leica Microsystems, Groot Bijgaarden, Belgium).

\section{Cell viability and morphology}

Cell viability analysis was performed by staining viable cells with $2 \mu \mathrm{M}$ calcein AM and dead cells with $4 \mu \mathrm{M}$ ethidium homodimer using the LIVE/DEAD Viability/ Cytotoxicity Kit (Invitrogen). On day 0, 7, 14 and 21, samples were analysed. After rinsing with $2 \mathrm{~mL}$ of PBS, 2D+ samples were covered immediately with the LIVE/ DEAD dye solution, while 3D samples were first cut in half and then stained. After placing the samples at $37^{\circ} \mathrm{C}$ for $20 \mathrm{~min}$ in the dark, the dye solution was discarded and residual stain was washed away with $2 \mathrm{~mL}$ of PBS. Cells were observed under a fluorescence microscope (Leica Microsystems) and a fluorescence stereomicroscope (Carl Zeiss, Zaventem, Belgium) equipped with digital imaging acquisition systems (SPOT digital camera, Diagnostic Instruments, Sterling Heights, MI, USA). Digital micrographs of cell viability, morphology and distribution were taken of the upper surface for the $2 \mathrm{D}+$ samples and of a cross-section for the 3D samples. Image processing of the micrographs was performed in Adobe Photoshop CS4 (Adobe Systems, Diegem, Belgium).

\section{Cell number}

To quantify the change in cell number during culture, the total amount of DNA per well, substrate or hydrogel was measured at day $0,7,14$, and 21 . For $2 \mathrm{D}$ culture, the cells were lysed in $300 \mu \mathrm{L}$ PBS containing $0.05 \%$ Triton X 100 (Sigma) and frozen at $-80^{\circ} \mathrm{C}$ until all the samples were collected for further processing. Then the samples were thawed and sonicated on ice to release all DNA from the nucleus. For 2D+ and 3D cultures, the samples were first frozen at $-80^{\circ} \mathrm{C}$ and subsequently DNA was extracted with the DNeasy Blood \& Tissue Kit (Qiagen, Venlo, The Netherlands). Each fibrin carrier was divided over four columns not to overload the membrane. The DNA content was measured with the Quant-iT High-Sensitivity DNA Assay Kit (Invitrogen) according to the manufacturer's protocol. To compare cell number between the different culture systems, the DNA content was normalised to the DNA content at the start of the experiment (day 0) for each condition. Additionally, a control experiment with known cell numbers ensured that the efficiencies of both isolation techniques were the same.

\section{Real-time quantitative PCR}

hPDCs are multipotent cells with the ability to differentiate both into the osteogenic and chondrogenic lineages (De Bari et al., 2006). Therefore, real-time quantitative PCR was performed to assess gene expression of osteogenic (alkaline phosphatase (ALP), collagen I (COL1), runtrelated transcription factor 2 (Runx2), and osteocalcin $(\mathrm{OCN})$ ) and chondrogenic markers (SRY-related HMGbox gene 9 (Sox9), aggrecan (ACAN), and collagen II (COL2)). RNA isolation was performed using the NucleoSpin RNAII Kit (Macherey-Nagel, Düren, Germany). After removing the medium, all samples were washed with $2 \mathrm{~mL}$ of PBS. The lysis buffer of the kit was added directly to the wells of the 2D cultures, while the fibrin hydrogels were first finely minced with a surgical knife before adding them to the lysis buffer. From there, RNA extraction was performed identically for all samples according to the manufacturer's protocol. Complementary DNA (cDNA) was obtained by reverse transcription of around $0.5 \mu \mathrm{g}$ of total RNA using the RevertAid H Minus First Strand cDNA Synthesis Kit (Fermentas, St.Leon-Rot, Germany). For quantitative analysis, real-time PCR was performed in duplicate on a Rotor-Gene 6000 system (Corbett, Westburg, Leusden, The Netherlands). Gene expression of ALP, COL1, Runx2, and Sox9 were measured using the Taqman Gene Expression Assays (Applied Biosystems, Lennik, Belgium). cDNA was amplified using the PerfeCTa qPCR FastMix UNG (Quanta Biosciences, Gaithersburg, MD, USA) under the following conditions: cDNA was first incubated for $2 \mathrm{~min}$ at $45^{\circ} \mathrm{C}$ and denatured for $30 \mathrm{~s}$ at $95^{\circ} \mathrm{C}$, followed by 40 cycles of 3 $\mathrm{s}$ at $95^{\circ} \mathrm{C}$ and $20 \mathrm{~s}$ at $60^{\circ} \mathrm{C}$. For the genes of interest, fold induction and expression levels were calculated using the comparative $\mathrm{Ct}$ method formula $\left(2^{-\Delta \mathrm{Ct}}\right.$, where $\Delta \mathrm{Ct}$ is the difference between $\mathrm{Ct}$ target and $\mathrm{Ct}$ reference) after normalisation to GAPDH. Gene expression of OCN was measured relatively to the expression of $\beta$-actin by amplifying cDNA with the Fast SYBR Green Master Mix (Applied Biosystems). cDNA was denatured for $3 \mathrm{~min}$ at $95^{\circ} \mathrm{C}$, followed by 40 cycles of $3 \mathrm{~s}$ at $95^{\circ} \mathrm{C}$ and $60 \mathrm{~s}$ at $60^{\circ} \mathrm{C}$. (Taqman assay numbers: hGAPDH: Hs99999905_m1, ALP: Hs00758162_m1, COL1: Hs00164004_m1, Runx2: Hs00231692_m1, Sox9: Hs00165814_m1, ACAN: Hs00153936_m1, COL2: Hs01064869_m1.SYBR Green primer sequences: $\beta$-actin: forward 5' - CCCAGATCATGTTTGAGACCT -3' reverse 5' - CCTCGTAGATGGGCACAGT-3', OCN: forward 5'GTGCAGCCTTTGTGTCCAA-3' reverse 5' GCTCACACACCTCCCTCCT-3').

\section{Statistical analysis}

Results are represented as mean \pm SEM of at least four different samples. Comparative studies were performed using a nonparametric two-sided Wilcoxon rank sum test. Results were declared significant if the $p$-value was less than 0.05. Calculations were performed using Matlab (The Mathworks, Eindhoven, The Netherlands). 
a

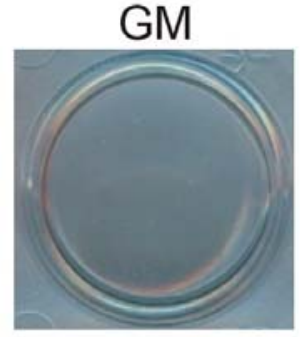

OM

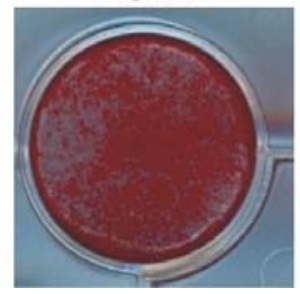

SFM

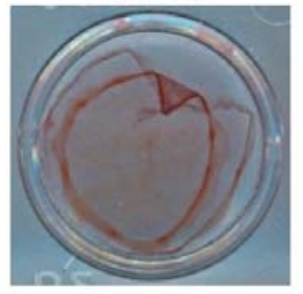

$\mathrm{OM}+\mathrm{TEA}$

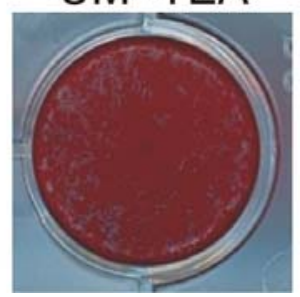

b

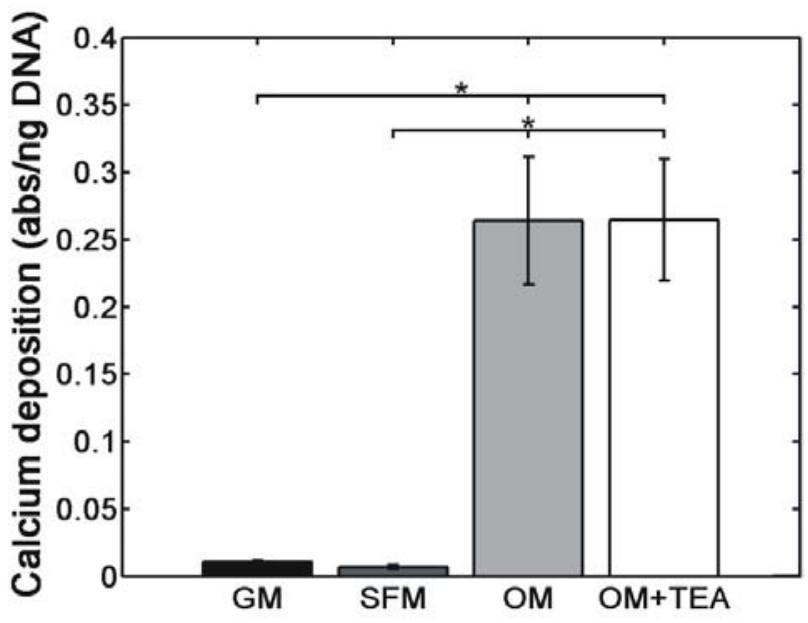

Fig. 2. (a) Alizarin red staining of calcium deposition by human periosteum derived cells (hPDCs) after 3 weeks of culture in 12-well plates in growth medium (GM), serum-free medium (SFM), osteogenic medium (OM), and osteogenic medium with tranexamic acid (OM+TEA). (b) Quantification of calcium deposition at day 21 by absorbance measurement of solubilised alizarin red $\mathrm{S}$ relative to the total DNA content. Results represent the mean \pm SEM of 4 samples. Statistically significant differences $(p<0.05)$ are denoted with an asterisk.

\section{Results}

\section{Effect of tranexamic acid on calcium deposition in} 2D

hPDCs cultured in OM for 3 weeks formed large nodules, as determined by alizarin red staining (Fig. 2a). Calcium deposits were not detected in growth medium and were discretely present in serum-free medium without osteogenic supplements. Absorbance levels of solubilised alizarin red S (relative to total DNA content) were significantly higher for OM (with or without TEA) than for medium without osteogenic supplements (GM and SFM) (Fig. 2b). The relative absorbance levels were 25 times higher in OM (with or without TEA) compared to GM. The presence of TEA in the OM did not change the amount of calcium deposition/mineralisation, neither qualitatively (Fig. 2a) nor quantitatively (Fig. 2b).

\section{Histology}

Histological images of 2D+ samples showed that cells covered the upper surface of the hydrogel and formed a confluent cell sheet (Fig. 3a). Cells seeded on the top surface, tended not to migrate into the substrate as they were all found within less than $40 \mu \mathrm{m}$ from the surface (Fig. 3b). After 3 weeks, no alizarin red S positive staining was observed in neither the 2D+ nor the 3D samples (data not shown).

In the absence of TEA, 3D samples degraded noticeably. After 3 weeks the cylindrical hydrogels were reduced to small beads with a diameter of approximately $1 \mathrm{~mm}$ (Fig. 3c). Towards the centre of these constructs cells appeared to be pyknotic, which is indicative for cell death (Fig. 3d). The addition of TEA to the medium successfully stabilised the shape and volume of the hydrogels (Fig. 3e). On the carrier surface a thick cell sheet formed that consisted of multiple cell layers and that reached a thickness of more than $100 \mu \mathrm{m}$ at some places (Fig. 3f).

\section{Cell viability and morphology}

Fluorescence microscopy analysis showed that cells were able to attach to the fibrin substrate (Fig. 4a). Their elongated shape in 2D+ was similar to the morphology observed in 2D. After 3 weeks of culture, the number of cells increased noticeably which resulted in a dense cell sheet covering the surface of the fibrin substrate. This cell layer was composed of almost only viable cells (Fig. 4b). At day 0 of 3D culture, predominantly viable cells were found homogeneously distributed throughout the fibrin hydrogel (Fig. 5). In contrast to the elongated morphology observed in 2D+, cells tended to remain mostly round in 3D. After 7 days of 3D culture, cell viability remained high and homogeneous within the fibrin carriers (Fig. 6a and $6 \mathrm{~b}$ ). However, a central region with higher numbers of dead cells was visible at day 14 in both OM and OM+TEA treated samples (Fig. 6c and 6d, respectively). Due to the significant reduction in size, the LIVE/DEAD assay could not be repeated at day 21 for the OM treated samples. In OM+TEA treated samples, the central region with higher number of dead cells had become larger by day 21 (Fig. 6e). These findings were different from preliminary experiments with fibrin carriers cultured in growth medium, for which hPDCs were found to be viable throughout the entire carrier up to 4 weeks of in vitro culture (Fig. 7).

\section{Cell number}

Comparison of relative increase in cell number showed that cell growth in 2D was unaffected by the presence of TEA (Fig. 8). Furthermore, in 2D+ hPDCs grew faster 

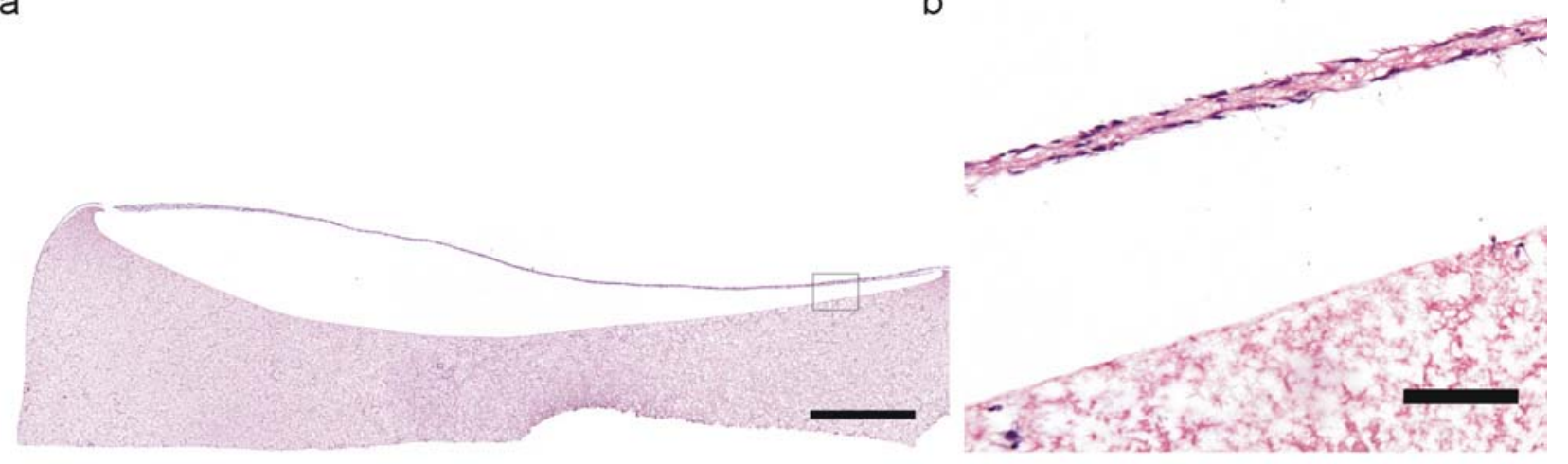

C

d

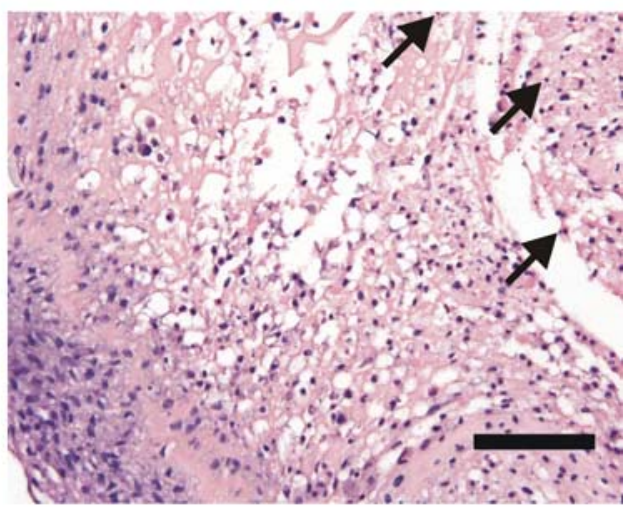

e
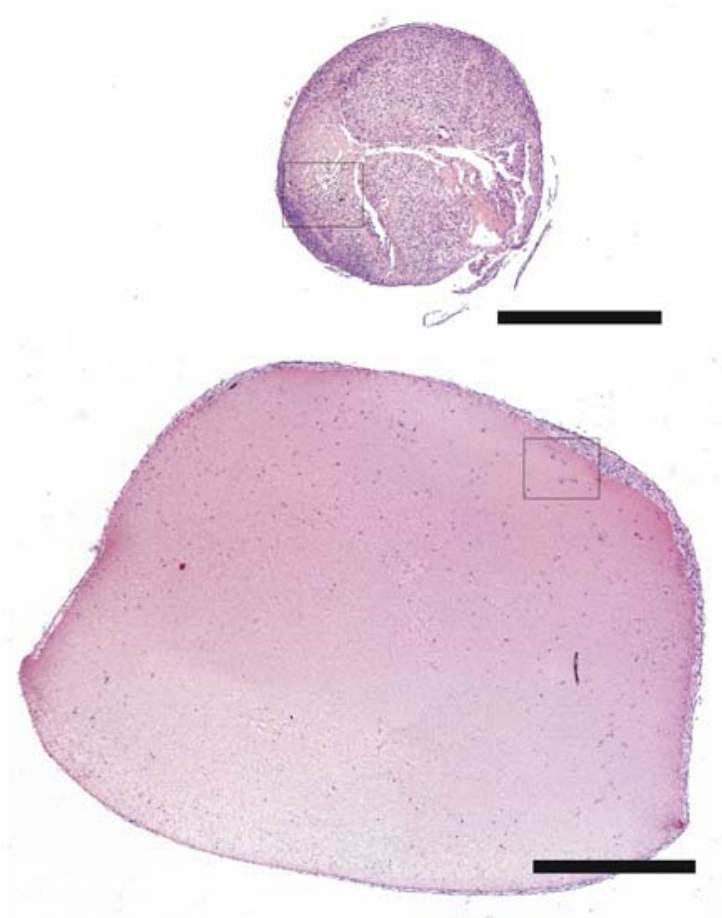

f

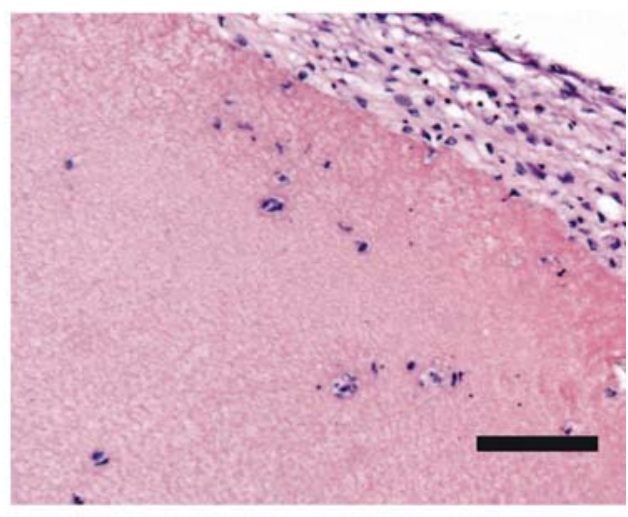

Fig. 3. H\&E staining on sections of fibrin hydrogels after 3 weeks of culture. Human periosteum derived cells (hPDCs) were seeded on the top surface of fibrin substrates (2D+) or encapsulated in fibrin carriers (3D) and cultured in osteogenic medium with or without tranexamic acid (OM+TEA and OM, respectively). (a-b) 2D+OM+TEA, (cd) 3D OM, and (e-f) 3D OM+TEA. In the right column $(\mathbf{b}, \mathbf{d}, \mathbf{f})$ a detail (bar $=100 \mu \mathrm{m})$ of the corresponding image (a, c, e) in the left column (bar = $1 \mathrm{~mm}$ ) can be found. The cell sheet that covered the surface of the 2D+ samples (ab), came loose from the fibrin substrate during histological preparation. Black arrows indicate apparent pycnotic cells.

and to a higher relative number compared to $2 \mathrm{D}$ : by day 21 the amount of DNA had increased 123 times in 2D+ while only 56 times in 2D (both in the presence of OM+TEA). On the other hand, cell growth in 3D was limited with only a 3.5 and 5.5 -fold increase in cell number after 21 days in OM and OM+TEA, respectively.

\section{Cell differentiation}

For the 2D culture group there was no evidence for upregulation for any of the osteogenic genes investigated, relative to day 0 when cultured in GM. On the other hand, in the presence of OM, ALP gene expression increased until it reached a maximal value around day 14 (Fig. 9a). Runx 2 expression peaked at day 7 and remained nearly constant afterwards (Fig. 9b). COL1 expression increased steadily (Fig. 9c), while there was no clear upregulation of OCN expression (Fig. 9d). Sox9 was maximally expressed around day 7, but decreased to its initial expression level afterwards (Fig. 9e). Some small differences were seen in the expression levels of the osteogenic markers for hPDCs cultured in OM versus OM+TEA, but only the ALP expression level at day 14 was significantly lower in the presence of TEA. Nevertheless, the rise in ALP gene expression during the first 2 weeks was clearly preserved.

The relative gene expression levels and profiles (temporal evolution) for specific markers were altered when changing the substrate from culture plastic to fibrin. 

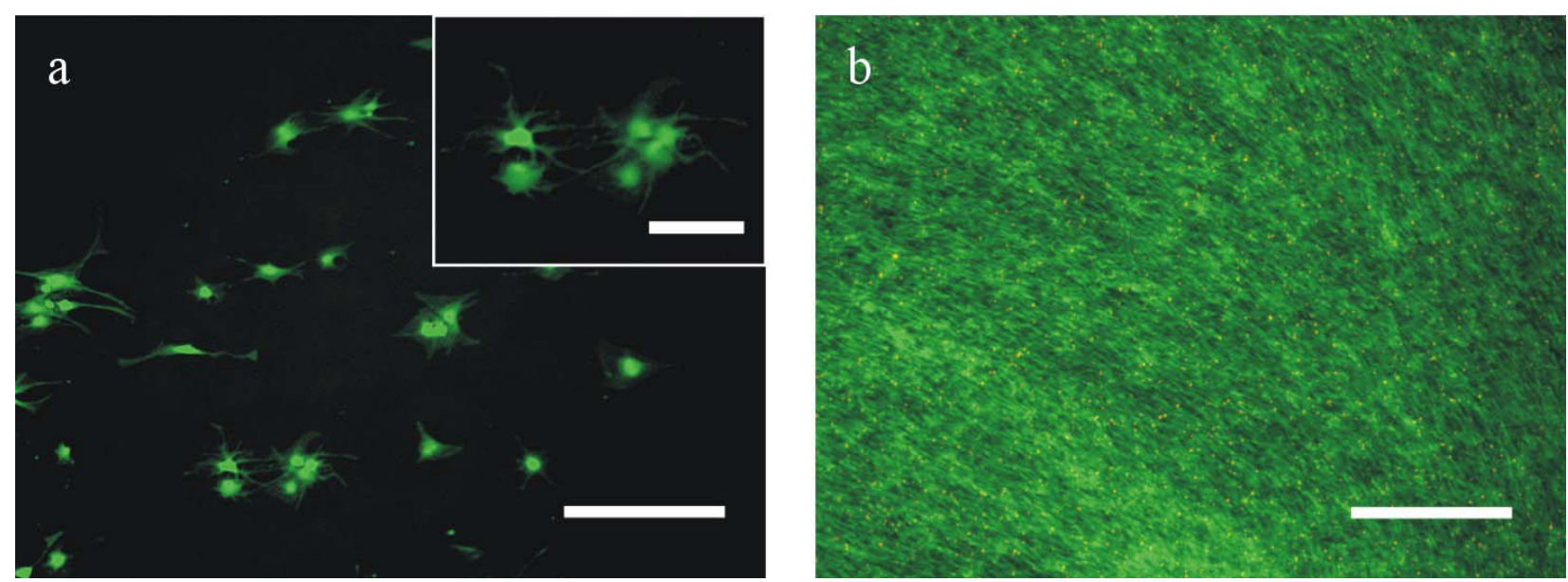

Fig. 4. LIVE/DEAD image of human periosteum derived cells (hPDCs) seeded on the top surface of a fibrin substrate in OM+TEA at day 0 (a) and day 21 (b). Bar $=300 \mu \mathrm{m}$, bar of insert in (a) $=100 \mu \mathrm{m}$.

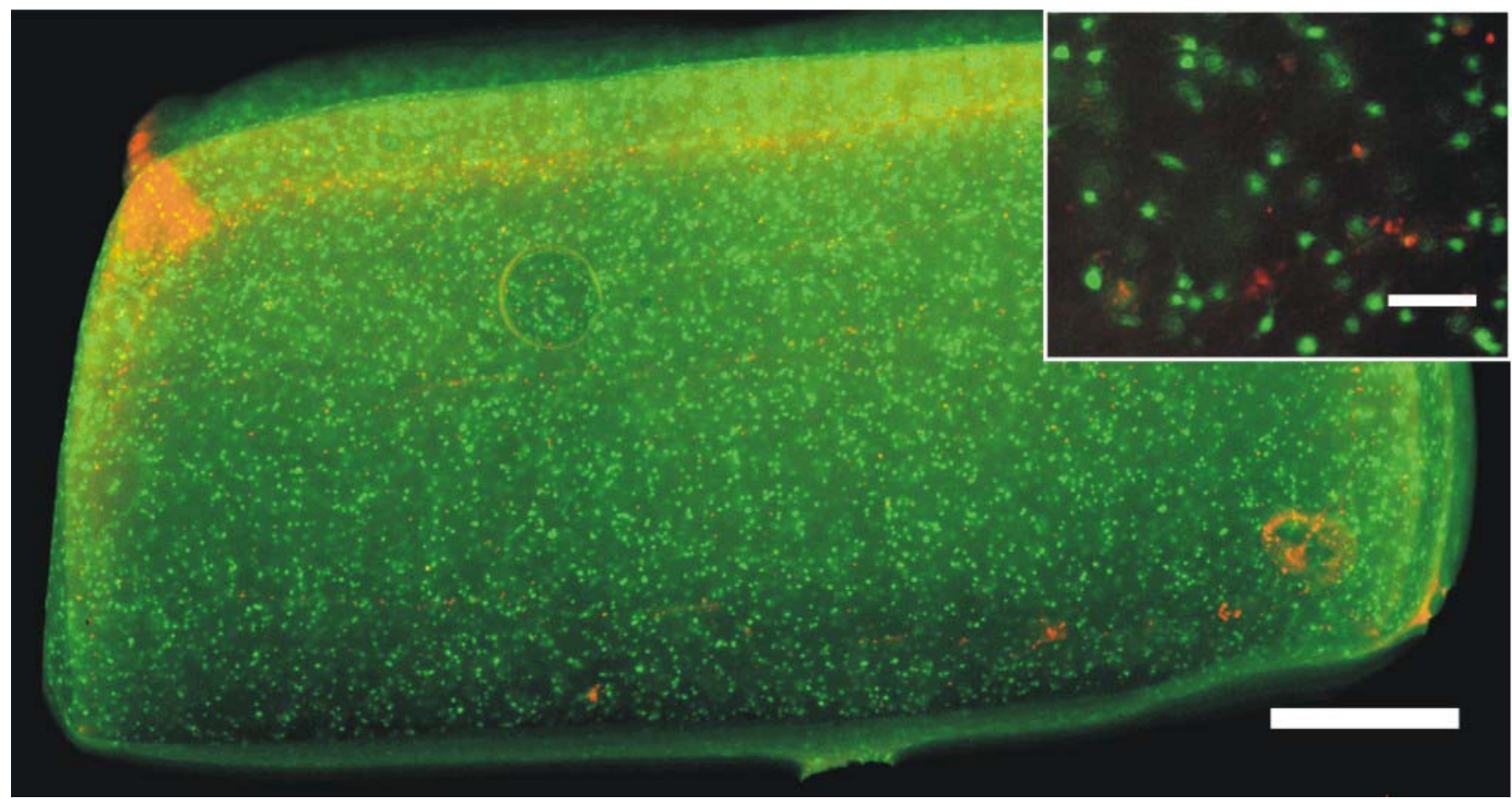

Fig. 5. LIVE/DEAD image of human periosteum derived cells (hPDCs) encapsulated in fibrin carriers at day 0. Bar $=1 \mathrm{~mm}$, bar of insert $=100 \mu \mathrm{m}$.

In $2 \mathrm{D}+$, only a small increase in ALP expression was observed (Fig. 9a). Runx2 expression at day 7 was significantly lower, but from day 14 onwards a nearly constant expression was shown at a similar level as OM treated samples in 2D (Fig. 9b). In contrast, COL1 was expressed at significantly higher levels in 2D+ (Fig. 9c). Sox 9 and ACAN were expressed at higher levels at the start of the experiment, but its expression dropped quickly afterwards (Fig. 9e and 9f, respectively). Expression levels of the chondrogenic marker COL2 were below the detection limit for all conditions in 2D, 2D+ and 3D. hPDCs that were cultured in $3 \mathrm{D}$ had a drastically lower relative expression of osteogenic markers compared to cells cultured in 2D or 2D+when cultured in OM (+TEA). Actually, the expressions levels were more comparable to the levels that were found for the negative control in which a non-inductive medium was used (2D-GM). Compared to this negative control, only moderately higher expression of Runx 2 at day 7 and 21 and COL1 at day 7 were observed in 3D (Fig. 9b and 9c, respectively). Similar to 2D+, the expression of Sox 9 and ACAN were higher at the start of the experiment (day 0) as compared to 2D. For ACAN, these differences were not statically significant $(p>0.05)$.

\section{Discussion}

In this study, the interaction of a clinically relevant cell source (human periosteum-derived cells) with a clinically relevant carrier biomaterial (fibrin sealant) was investigated under osteogenic conditions. This in vitro approach was chosen to understand the influence of fibrin on the osteogenic behaviour of cells that are associated with a fibrin sealant and that are applied in vivo to promote 

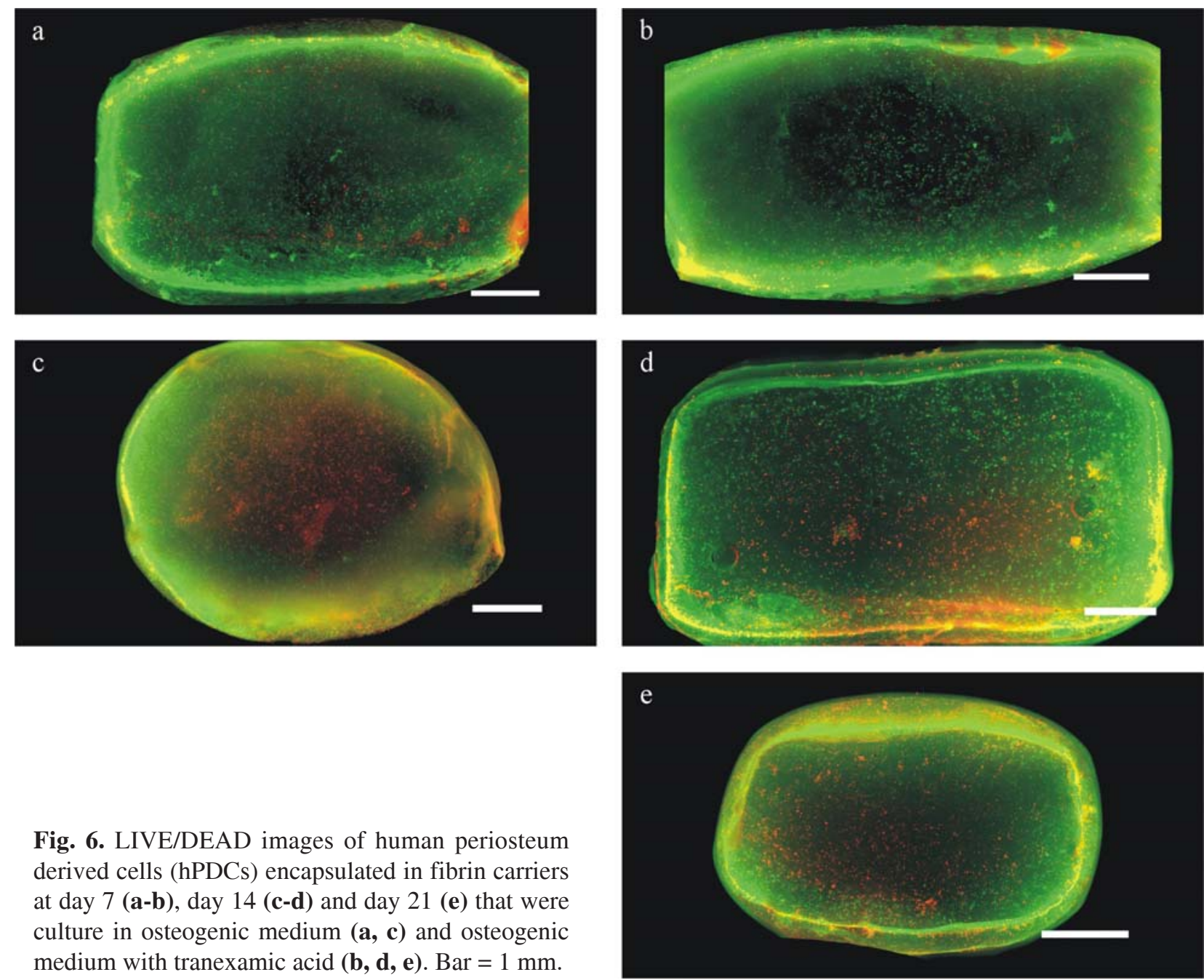

Fig. 6. LIVE/DEAD images of human periosteum derived cells (hPDCs) encapsulated in fibrin carriers at day 7 (a-b), day 14 (c-d) and day 21 (e) that were culture in osteogenic medium $(\mathbf{a}, \mathbf{c})$ and osteogenic medium with tranexamic acid $(\mathbf{b}, \mathbf{d}, \mathbf{e})$. Bar $=1 \mathrm{~mm}$.

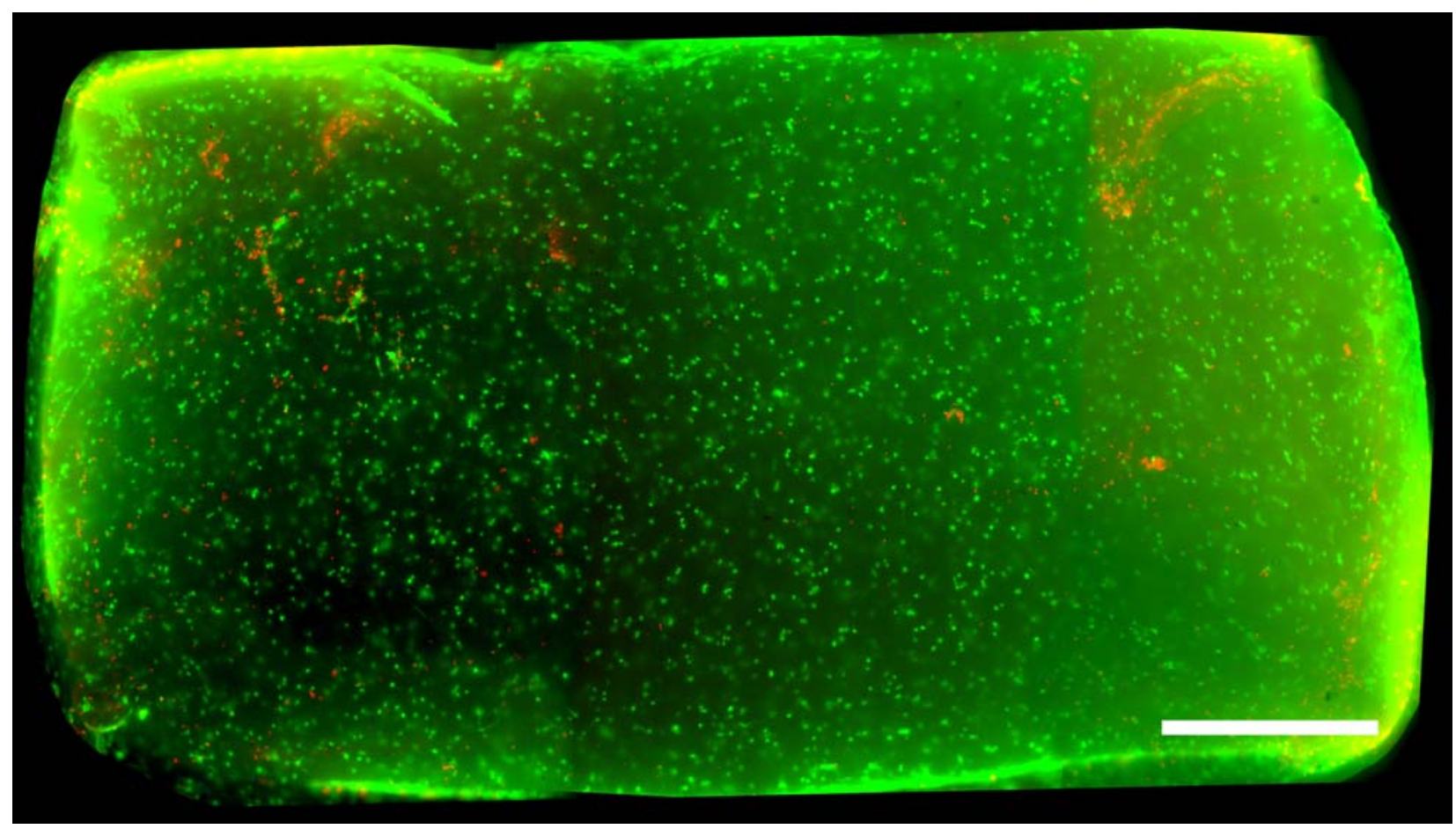

Fig. 7. LIVE/DEAD image of human periosteum derived cells (hPDCs) encapsulated in fibrin carriers that were cultured in growth medium with $250 \mathrm{KIU} / \mathrm{mL}$ aprotinin for 4 weeks. Bar $=1 \mathrm{~mm}$. 


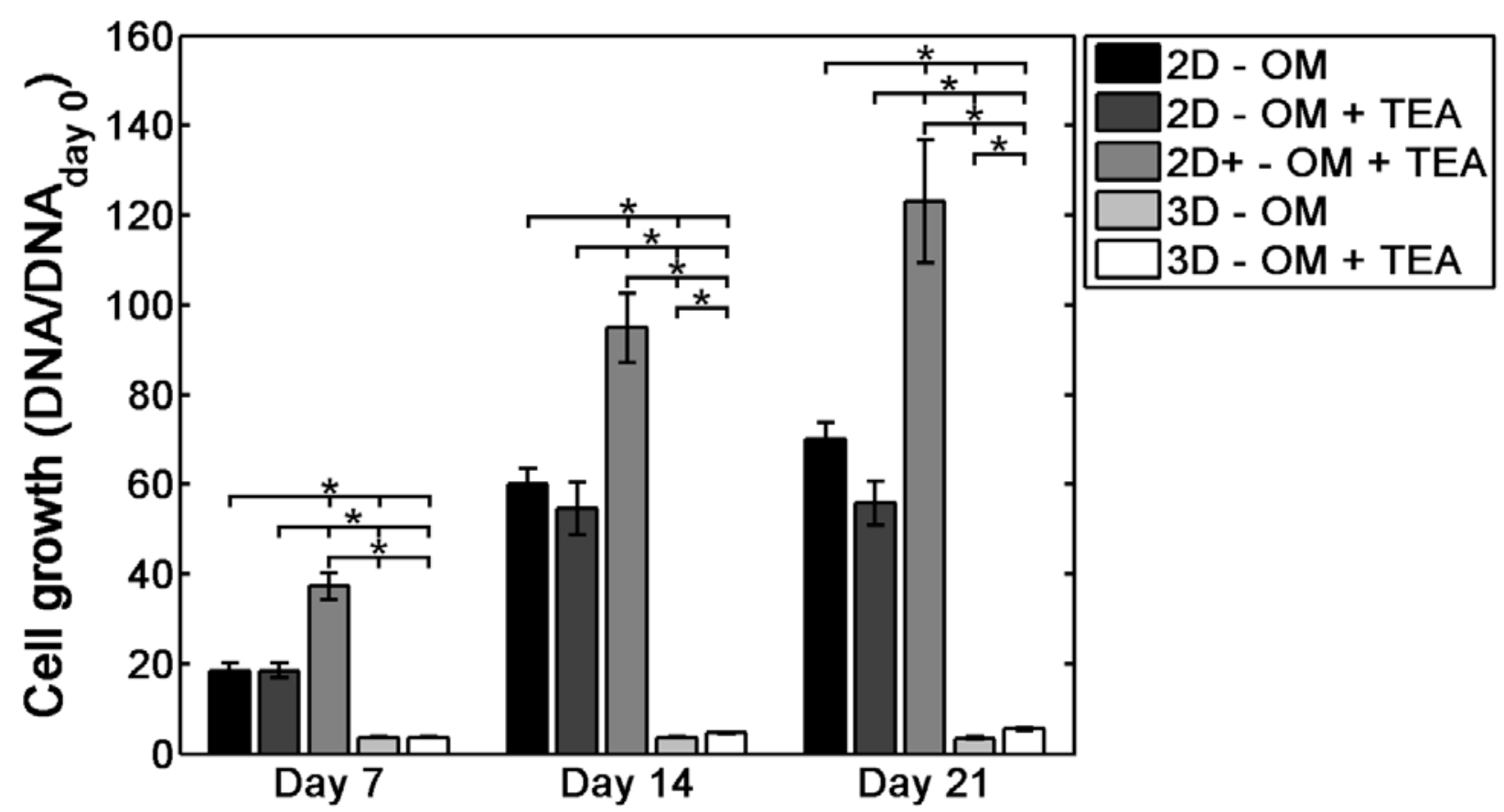

Fig. 8. Relative increase in cell number by measuring the total amount of DNA per sample weekly and normalising it to the DNA content at the start of the experiment (day 0) for each condition. Human periosteum derived cells (hPDCs) were seeded in 12-well plates (2D), on the top surface of fibrin substrates (2D+) or encapsulated in fibrin carriers (3D) and cultured in osteogenic medium with or without tranexamic acid (OM+TEA and OM, respectively). Results represent the mean \pm SEM of at least 4 samples. Statistically significant differences $(p<0.05)$ are denoted with an asterisk.

bone regeneration. First, hPDCs were seeded on fibrin substrates of at least $1 \mathrm{~mm}$ thick to allow them to both interact with the protein network and experience the matrix elasticity, similar to the situation when cells and fibrin are applied together as a coating on orthopaedic implants. Our results demonstrated that hPDCs adhered and spread on fibrin substrates. Comparison between the relative cell growth on fibrin substrates and on culture plastic indicated that cells grew faster and to higher densities on fibrin substrates.

The accelerated cell growth might have resulted from the interaction of the hPDCs with components of the fibrin sealant or from differences in substrate stiffness. The major components of fibrin, fibrinogen and thrombin, have both been found to stimulate proliferation of fibroblasts and osteoblasts when added to the culture medium or when bound to the cell culture substrate (Dawes et al., 1993; Gray et al., 1993; Gorodetsky et al., 1998; Frost et al., 1999). Besides fibrinogen and thrombin, fibrin sealants can also contain active growth factors including TGF- $\beta 1$ and bFGF (Cox et al., 2004). Although their precise concentrations are unknown and are likely to vary between manufacturers and even between batches, growth factors are known to enhance MSC proliferation, especially bFGF alone (Martin et al., 1997; Tsutsumi et al., 2001; Solchaga et al., 2005) or in combination with TGF- $\beta 1$ (Jung et al., 2010). In addition, the rigidity difference between culture plastic (Young's modulus of polystyrene is around 3000 $\mathrm{MPa}$ ) and fibrin substrates (Young's modulus around 19 $\mathrm{kPa}$ (Noailly et al., 2008)) might have altered cell growth, since substrate stiffness has been shown to modulate MSC proliferation (Chen et al., 2010). Chen et al. reported that MSC proliferation was maximised on fibronectin-coated polyacrylamide substrates with a Young's modulus between $10 \mathrm{kPa}$ and $20 \mathrm{kPa}$. When the substrate's modulus was increased (values up to $144.5 \mathrm{kPa}$ were investigated), MSC proliferation was found to reduce drastically. Although fibronectin is present in fibrin sealants, direct translation of these results to fibrin is difficult since MSC mechanoresponsiveness was dependent on the ECM protein used to coat the polyacrylamide substrates (Chen et al., 2010). Furthermore, it is likely that a reduced contact inhibition and more multilayered cell growth have contributed to the higher cell density found on fibrin substrates after 3 weeks of in vitro culture. In 2D culture cell growth is arrested between day 7 and 14, while a similar plateau in cell growth is not present in $2 \mathrm{D}+$ cultures. Histological examination showed cells clearly growing on top of each other in 2D+cultures. This observation suggests that the multilayered cell growth, which is common in OM (Jaiswal et al., 1997), was enhanced on the degradable fibrin substrate as compared to culture plastic.

The osteogenic potential of the hPDCs was confirmed by means of the calcium deposition and gene expression results for 2D culture. However, the absence of a clear increase of OCN expression suggested that the cells did not reach full osteogenic differentiation after 3 weeks. When cultured on fibrin substrates, hPDCs altered their gene expression. During 2D+ culture, COL1 expression was increased compared to plastic. However, the reduced 
a

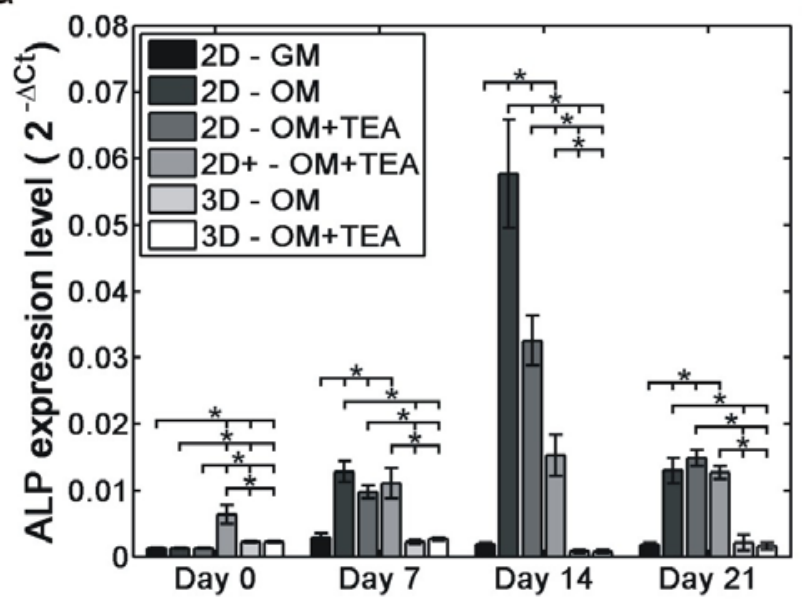

C

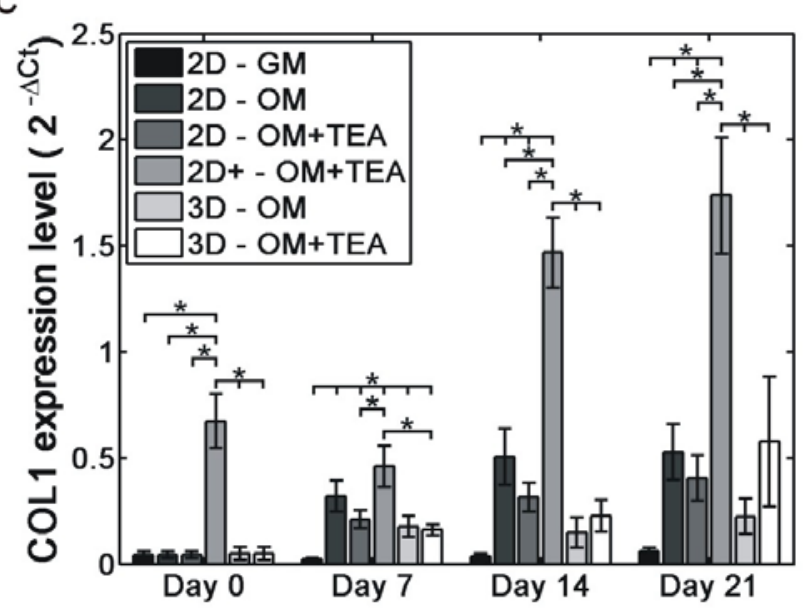

e

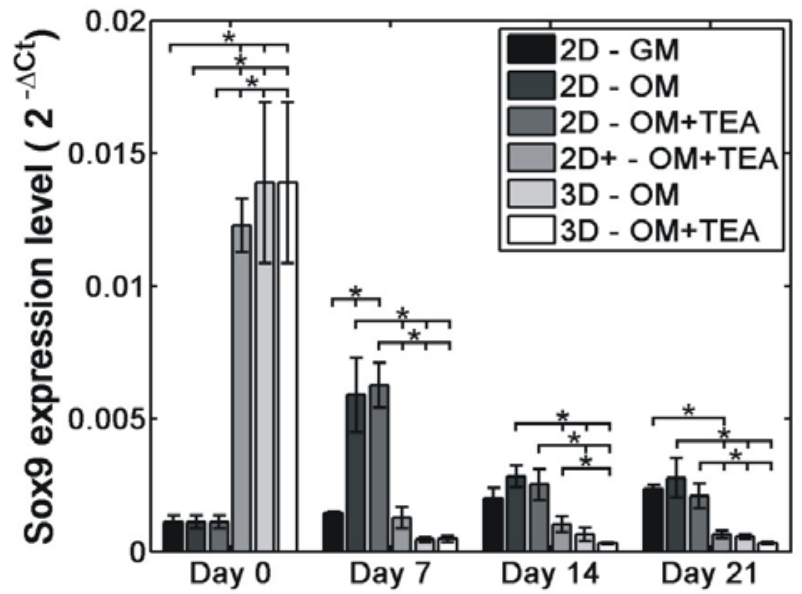

$\mathrm{b}$

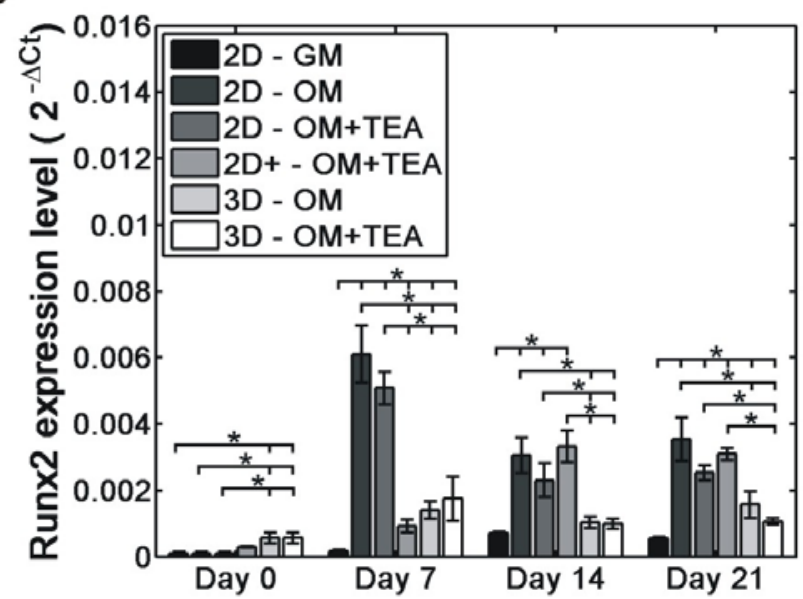

d

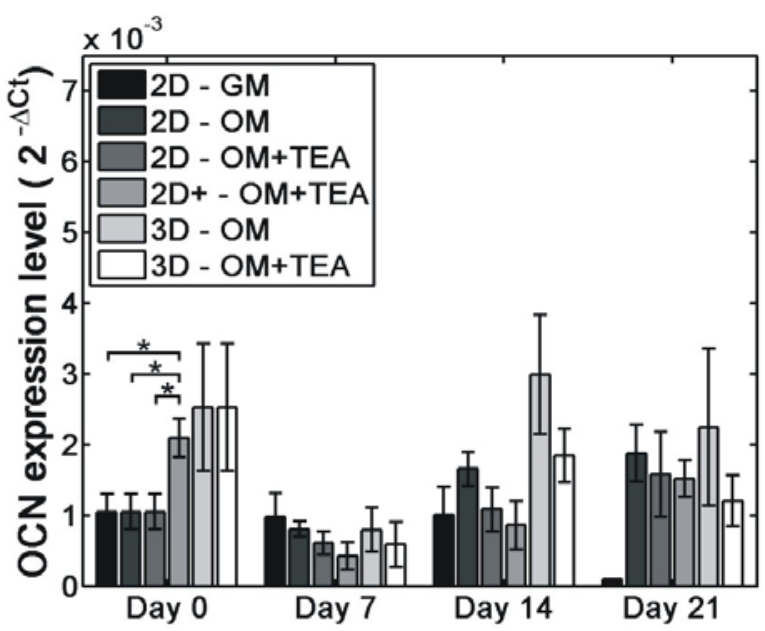

$f$

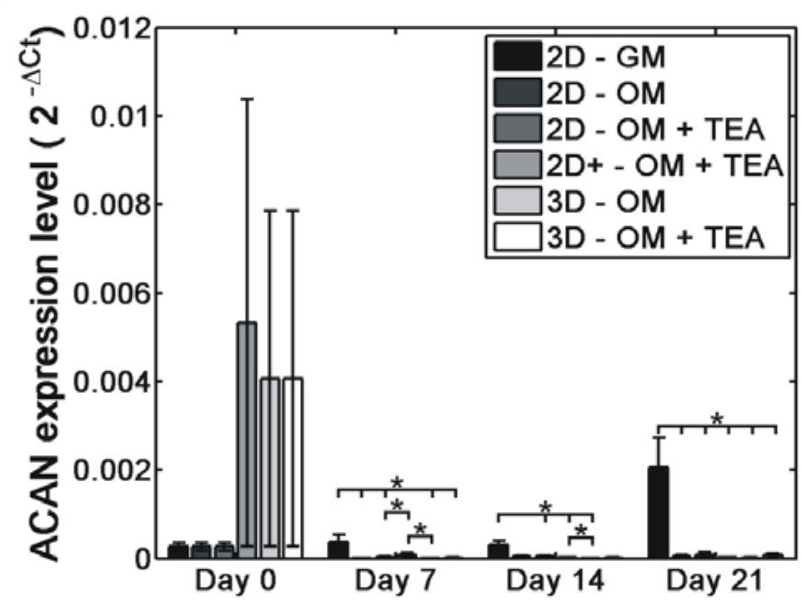

Fig. 9. Real-time quantitative PCR analysis of the gene expression of osteogenic markers (a to d) alkaline phosphatase (ALP), runt-related transcription factor 2 (Runx2), collagen I (COL1), and osteocalcin (OCN) and chondrogenic markers (e to f) Sox9 and aggrecan (ACAN). The results are shown for hPDCs that were seeded in 12-well plates (2D), on the top surface of fibrin substrates (2D+) or encapsulated in fibrin carriers (3D) and cultured in osteogenic medium with or without tranexamic acid (OM+TEA and OM, respectively). Results represent the mean \pm SEM of at least 4 samples. Statistically significant differences $(p<0.05)$ are denoted with an asterisk.

expression of the more specific osteogenic markers Runx2 and ALP suggests that the fibrin substrates stimulated hPDC proliferation at the expense of a reduction or delay in osteogenic differentiation.

Encapsulating hPDCs in fibrin resulted in a homogeneous cell distribution in the $3 \mathrm{D}$ carrier. The rounded cell morphology indicates that cells failed to spread in this carrier. In contrast to $2 \mathrm{D}+$ cultures, cell growth was reduced significantly in 3D cultures compared to $2 \mathrm{D}$ cultures. This corresponds with previous observations with bone marrow MSCs (Bensaid et al., 2003; Catelas et al., 2006). However in contrast to Catelas et al., who reported that bone marrow MSCs started to differentiate into the osteogenic lineage in fibrin hydrogels 
containing a high $(34 \mathrm{mg} / \mathrm{mL})$ fibrinogen concentration (Catelas et al., 2006), none of the osteogenic markers was upregulated in hPDCs during 3D culture in this study. With regard to the osteogenic genes, hPDCs displayed an undifferentiated phenotype in 3D culture similar to hPDCs in $2 \mathrm{D}$ culture with growth medium (negative control). As compared to $2 \mathrm{D}$, higher relative expression levels for all investigated genes (especially Sox9) were measured at the start of 2D+ and 3D cultures. Differences in the preparation of the samples, which led to slight differences in terms of the definition of the 'day 0' condition (i.e. start of treatment with serum-free osteogenic medium), might also have contributed to the differences in gene expression at day 0 . 2D samples were prepared by seeding cells in serumcontaining growth medium (10\% FBS), in order to promote cell attachment to plastic. Cells were allowed to attach overnight before the treatment with serum-free osteogenic medium was started. As a result, the start of the treatment ('day 0') in 2D was one day after seeding the cells. In 2D+ and 3D, treatment with serum-free osteogenic medium was started on the same day of cell seeding/encapsulation. Switching from serum-containing to serum-free medium was not done within the presence of fibrin gel, in order to avoid diffusion of serum components into the gel. This would have led to a poorly defined (uncontrolled) 'day 0' condition, as replacing serum-containing with serum-free medium and washing the gels are not sufficient to guarantee the removal of all serum components from the gel. From day 14 , increased cell death was observed in the fibrin carriers. Hence, the 3D culture environment was insufficient to ensure cell viability for longer in vitro culture. Interestingly, the occurrence of increased cell death was found to depend on the medium used during 3D culture. When growth medium was used instead of osteogenic medium, cell viability was maintained throughout the entire fibrin hydrogels after 4 weeks of in vitro culture. Since regions with increased cell death were always located in the centre of OM and OM+TEA treated carriers, it is likely that nutrient transfer to this region was inadequate. Possibly, cellular metabolic activity and nutrient requirements may have varied between growth medium and osteogenic medium. Hydrogel carriers that rely only on diffusion for their nutrient supply have been reported to give rise to regions with increased cell number near the surface and reduced viability in the centre (Volkmer et al., 2008). These inhomogeneous cell distributions have been associated with oxygen gradients that may arise due to high metabolic activity of cells and limited diffusion within the hydrogel (Radisic et al., 2006). Shorter diffusion distances and active perfusion of the medium might overcome these limitations (Eniwumide et al., 2009).

Degradability is an important requirement of a biological implant. However, fibrin-based constructs often disintegrate too fast to maintain their shape and mechanical properties during in vitro culture of multiple weeks. Certain control over the degradation rate of fibrin-based constructs is required to perform in vitro experiments or to precondition cell-seeded implants in vitro prior to in vivo implantation. Antifibrinolytic agents can be added to these products to slow down the degradation of the constructs. Aprotinin and TEA are the most commonly used antifibrinolytic agents in fibrin sealants (Busuttil, 2003), the former being present in the fibrinogen solution of Tisseel. Aprotinin is a natural proteinase inhibitor that is derived from bovine lung (Hardy and Desroches, 1992), while TEA is a synthetic derivative of the amino acid lysine (Dunn and Goa, 1999). TEA exerts its antifibrinolytic effect by blocking lysine binding sites on plasmin(ogen) molecules and thereby inhibiting the binding of plasmin to fibrin. TEA is 6 to 10 times more potent in terms of binding to plasmin(ogen) than $\varepsilon$-aminocaproic acid, another synthetic antifibrinolytic agent (Dunn and Goa, 1999). As the integrity of the Tisseel fibrin sealant was found to be insufficient for prolonged in vitro culture, an additional antifibrinolytic agent was supplemented to the medium. TEA was selected instead of aprotinin, because of the recent withdrawal of aprotinin for clinical use for safety reasons (Murkin, 2009). We observed that $0.5 \mathrm{mg} /$ $\mathrm{mL}$ of TEA successfully stabilised the fibrin hydrogels. The influence of TEA on the proliferation and osteogenic differentiation of hPDCs on culture plastic was tested in 2D culture. While proliferation and mineralisation were not affected by TEA, expression levels of ALP, Runx2, COL1 and OCN were slightly reduced. These differences between $\mathrm{OM}$ and $\mathrm{OM}+\mathrm{TEA}$ were however not statistically significant, except for a reduction in ALP expression at day 14. Nevertheless, for all investigated genes, TEA did not affect the gene expression profiles (same temporal evolution).

As to the role of fibrin in enhancing in vivo bone regeneration, the results of this study may suggest that fibrin serves primarily as a cell delivery vehicle that allows for a homogeneous distribution and confinement of sufficient amounts of osteoprogenitor cells into the defect site. The reduction (for 2D+: reduced ALP and Runx2 expression and no mineralisation in comparison to 2D) and absence (for 3D: similar gene expression levels as in negative control) of osteogenic differentiation when hPDCs are associated with fibrin, demonstrates that in vitro osteogenic differentiation of hPDCs is at least partially impaired by fibrin or other factors contained in the fibrin sealant as compared to culture plastic. As a result, the previously reported positive in vivo outcomes on the use of fibrin sealant as a cell carrier for bone formation or repair (Tholpady et al., 1999; Isogai et al., 2000; Perka et al., 2000; Kalia et al., 2009), may be more related to the delivery and containment of sufficient amounts of cells, in combination with signals that are present in the local in vivo environment.

\section{Conclusions}

This study investigated the in vitro viability, proliferation and differentiation of hPDCs when cultured on or in fibrin sealant under osteogenic conditions. In this way, the impact of the dimensionality of hPDC-fibrin constructs was considered when evaluating fibrin's influence on hPDC behaviour. On fibrin substrates, hPDC proliferation was 
enhanced as compared to culture plastic. At the same time, no mineralisation was observed and gene expression levels of the osteogenic markers ALP and Runx2 were significantly reduced. In fibrin carriers, viable hPDCs were homogeneously distributed up to 1 week of culture. However, both the proliferation rate and relative expression of osteogenic markers were reduced in 3D culture, compared to $2 \mathrm{D}$ and $2 \mathrm{D}+$, even after 1 week when cell viability was still maintained. These results may suggest that fibrin sealant impairs osteogenesis when applied in combination with hPDCs, as compared to culture plastic, irrespective of the dimensionality of the hPDC-fibrin construct. TEA at a concentration of $0.5 \mathrm{mg} / \mathrm{mL}$ was found to be a suitable medium supplement to maintain fibrin integrity and size during in vitro culture, without affecting cell proliferation and calcium deposition and with minor effects on the osteogenic differentiation of hPDCs.

\section{Acknowledgements}

The authors thank Carla Geeroms and Kathleen Bosmans for assistance with RNA isolation and histological sectioning. The authors are also grateful to Baxter Innovations GmbH (Vienna, Austria) for providing the fibrin components. This work is part of Prometheus, the Leuven Research \& Development Division of Skeletal Tissue Engineering of the Katholieke Universiteit Leuven (www.kuleuven.be/prometheus). This work was supported by the Research Foundation-Flanders (FWO-Vlaanderen, project number G.0307.06N).

\section{References}

Abiraman S, Varma HK, Umashankar PR, John A (2002) Fibrin glue as an osteoinductive protein in a mouse model. Biomaterials 23: 3023-3031.

Arnsdorf EJ, Jones LM, Carter DR, Jacobs CR (2009) The periosteum as a cellular source for functional tissue engineering. Tissue Eng Part A 15: 2637-2642.

Bensaid W, Triffitt JT, Blanchat C, Oudina K, Sedel L, Petite H (2003) A biodegradable fibrin scaffold for mesenchymal stem cell transplantation. Biomaterials 24: 2497-2502.

Blomback B (1996) Fibrinogen and fibrin-proteins with complex roles in hemostasis and thrombosis. Thromb Res 83: 1-75.

Brittberg M, Jansson ES, Lindahl A, Peterson L (1997) Influence of fibrin sealant (Tisseel) on osteochondral defect repair in the rabbit knee. Biomaterials 18: 235-242.

Busuttil RW (2003) A comparison of antifibrinolytic agents used in hemostatic fibrin sealants. J Am Coll Surg 197: 1021-1028.

Carmagnola D, Berglundh T, Araujo M, Albrektsson T, Lindhe J (2000) Bone healing around implants placed in a jaw defect augmented with Bio-Oss. An experimental study in dogs. J Clin Periodontol 27: 799-805.

Catelas I, Sese N, Wu BM, Dunn JC, Helgerson S, Tawil B (2006) Human mesenchymal stem cell proliferation and osteogenic differentiation in fibrin gels in vitro. Tissue Eng 12: 2385-2396.

Chen WL, Likhitpanichkul M, Ho A, Simmons CA (2010) Integration of statistical modeling and high-content microscopy to systematically investigate cell-substrate interactions. Biomaterials 31: 2489-2497.

Cholewinski E, Dietrich M, Flanagan TC, SchmitzRode T, Jockenhoevel S (2009) Tranexamic acid - an Alternative to Aprotinin in Fibrin-Based Cardiovascular Tissue Engineering. Tissue Eng Part A 15: 3645-3653.

Cox S, Cole M, Tawil B (2004) Behavior of human dermal fibroblasts in three-dimensional fibrin clots: dependence on fibrinogen and thrombin concentration. Tissue Eng 10: 942-954.

Cunin G, Boissonnet H, Petite H, Blanchat C, Guillemin G (2000) Experimental vertebroplasty using osteoconductive granular material. Spine 25: 1070-1076.

Dawes KE, Gray AJ, Laurent GJ (1993) Thrombin stimulates fibroblast chemotaxis and replication. Eur J Cell Biol 61: 126-130.

De Bari C, Dell'Accio F, Vanlauwe J, Eyckmans J, Khan IM, Archer CW, Jones EA, McGonagle D, Mitsiadis TA, Pitzalis C, Luyten FP (2006) Mesenchymal multipotency of adult human periosteal cells demonstrated by single-cell lineage analysis. Arthritis Rheum 54: 12091221.

Dunn CJ, Goa KL (1999) Tranexamic acid: a review of its use in surgery and other indications. Drugs 57: 10051032.

Eniwumide JO, Lee DA, Bader DL (2009) The development of a bioreactor to perfuse radially-confined hydrogel constructs: design and characterization of mass transport properties. Biorheology 46: 417-437.

Eyckmans J, Luyten FP (2006) Species specificity of ectopic bone formation using periosteum-derived mesenchymal progenitor cells. Tissue Eng 12: 2203-2213.

Eyckmans J, Roberts SJ, Schrooten J, Luyten FP (2010) A clinically relevant model of osteoinduction: a process requiring calcium phosphate and BMP/Wnt signalling. J Cell Mol Med 14: 1845-1856.

Eyrich D, Brandl F, Appel B, Wiese H, Maier G, Wenzel M, Staudenmaier R, Goepferich A, Blunk T (2007) Longterm stable fibrin gels for cartilage engineering. Biomaterials 28: 55-65.

Friedenstein AJ, Piatetzky-Shapiro II, Petrakova KV (1966) Osteogenesis in transplants of bone marrow cells. J Embryol Exp Morphol 16: 381-390.

Frost A, Jonsson KB, Ridefelt P, Nilsson O, Ljunghall S, Ljunggren O (1999) Thrombin, but not bradykinin, stimulates proliferation in isolated human osteoblasts, via a mechanism not dependent on endogenous prostaglandin formation. Acta Orthop Scand 70: 497-503.

Gorodetsky R, Vexler A, An J, Mou X, Marx G (1998) Haptotactic and growth stimulatory effects of fibrin(ogen) and thrombin on cultured fibroblasts. J Lab Clin Med 131: 269-280.

Gray AJ, Bishop JE, Reeves JT, Laurent GJ (1993) A alpha and B beta chains of fibrinogen stimulate proliferation of human fibroblasts. J Cell Sci 104: 409413. 
Hardy JF, Desroches J (1992) Natural and synthetic antifibrinolytics in cardiac surgery. Can J Anaesth 39: 353 365.

Huang CY, Deitzer MA, Cheung HS (2007) Effects of fibrinolytic inhibitors on chondrogenesis of bone-marrow derived mesenchymal stem cells in fibrin gels. Biomech Model Mechanobiol 6: 5-11.

Isogai N, Landis WJ, Mori R, Gotoh Y, Gerstenfeld LC, Upton J, Vacanti JP (2000) Experimental use of fibrin glue to induce site-directed osteogenesis from cultured periosteal cells. Plast Reconstr Surg 105: 953-963.

Jackson MR (2001) Fibrin sealants in surgical practice: An overview. Am J Surg 182: 1S-7S.

Jaiswal N, Haynesworth SE, Caplan AI, Bruder SP (1997) Osteogenic differentiation of purified, cultureexpanded human mesenchymal stem cells in vitro. J Cell Biochem 64: 295-312.

Jarzem P, Harvey EJ, Shenker R, Hajipavlou A (1996) The effect of fibrin sealant on spinal fusions using allograft in dogs. Spine 21: 1307-1312.

Jung S, Sen A, Rosenberg L, Behie LA (2010) Identification of growth and attachment factors for the serum-free isolation and expansion of human mesenchymal stromal cells. Cytotherapy 12: 637-657.

Kalia P, Coathup MJ, Oussedik S, Konan S, Dodd M, Haddad FS, Blunn GW (2009) Augmentation of bone growth onto the acetabular cup surface using bone marrow stromal cells in total hip replacement surgery. Tissue Eng Part A 15: 3689-3696.

Kania RE, Meunier A, Hamadouche M, Sedel L, Petite H (1998) Addition of fibrin sealant to ceramic promotes bone repair: long-term study in rabbit femoral defect model. J Biomed Mater Res 43: 38-45.

Kupcsik L, Alini M, Stoddart MJ (2009) Epsilonaminocaproic acid is a useful fibrin degradation inhibitor for cartilage tissue engineering. Tissue Eng Part A 15: 2309-2313.

Lee CR, Grad S, Gorna K, Gogolewski S, Goessl A, Alini M (2005) Fibrin-polyurethane composites for articular cartilage tissue engineering: a preliminary analysis. Tissue Eng 11: 1562-1573.

LeGuehennec L, Layrolle P, Daculsi G (2004) A review of bioceramics and fibrin sealant. Eur Cell Mater 8: 1-11.

Martin I, Muraglia A, Campanile G, Cancedda R, Quarto R (1997) Fibroblast growth factor-2 supports ex vivo expansion and maintenance of osteogenic precursors from human bone marrow. Endocrinology 138: 4456-4462.

McGee-Russell SM (1958) Histochemical methods for calcium. J Histochem Cytochem 6: 22-42.

Meinhart J, Fussenegger M, Hobling W (1999) Stabilization of fibrin-chondrocyte constructs for cartilage reconstruction. Ann Plast Surg 42: 673-678.

Mosesson MW, Siebenlist KR, Meh DA (2001) The structure and biological features of fibrinogen and fibrin. Ann N Y Acad Sci 936: 11-30.

Murkin JM (2009) Lessons learned in antifibrinolytic therapy: The BART trial. Semin Cardiothorac Vasc Anesth 13: $127-131$.

Nakahara H, Bruder SP, Haynesworth SE, Holecek JJ, Baber MA, Goldberg VM, Caplan AI (1990) Bone and cartilage formation in diffusion chambers by subcultured cells derived from the periosteum. Bone 11: 181-188.

Ng AM, Saim AB, Tan K, Tan GH, Mokhtar SA, Rose IM, Othman F, Idrus RBH (2005) Comparison of bioengineered human bone construct from four sources of osteogenic cells. J Orthop Sci 10: 192-199.

Noailly J, Van OH, Wilson W, Quinn TM, Ito K (2008) A poroviscoelastic description of fibrin gels. J Biomech 41: 3265-3269.

Perka C, Schultz O, Spitzer RS, Lindenhayn K, Burmester GR, Sittinger M (2000) Segmental bone repair by tissue-engineered periosteal cell transplants with bioresorbable fleece and fibrin scaffolds in rabbits. Biomaterials 21: 1145-1153.

Radisic M, Malda J, Epping E, Geng W, Langer R, Vunjak-Novakovic G (2006) Oxygen gradients correlate with cell density and cell viability in engineered cardiac tissue. Biotechnol Bioeng 93: 332-343.

Solchaga LA, Penick K, Porter JD, Goldberg VM, Caplan AI, Welter JF (2005) FGF-2 enhances the mitotic and chondrogenic potentials of human adult bone marrowderived mesenchymal stem cells. J Cell Physiol 203: 398409.

Tholpady SS, Schlosser R, Spotnitz W, Ogle RC, Lindsey WH (1999) Repair of an osseous facial criticalsize defect using augmented fibrin sealant. Laryngoscope 109: $1585-1588$.

Tsutsumi S, Shimazu A, Miyazaki K, Pan H, Koike C, Yoshida E, Takagishi K, Kato Y (2001) Retention of multilineage differentiation potential of mesenchymal cells during proliferation in response to FGF. Biochem Biophys Res Commun 288: 413-419.

Volkmer E, Drosse I, Otto S, Stangelmayer A, Stengele M, Kallukalam BC, Mutschler W, Schieker M (2008) Hypoxia in static and dynamic 3D culture systems for tissue engineering of bone. Tissue Eng Part A 14: 1331-1340.

Zuk PA, Zhu M, Mizuno H, Huang J, Futrell JW, Katz AJ, Benhaim P, Lorenz HP, Hedrick MH (2001) Multilineage cells from human adipose tissue: implications for cell-based therapies. Tissue Eng 7: 211-228.

\section{Discussion with Reviewer}

Reviewer II: One of the main conclusions of the paper seems to be the fibrin is not permissive for the osteogenic differentiation of hPDCs. As previous work has indicated human bone marrow derived MSCs are osteogenic in fibrin, could the authors speculate on the difference?

Authors: In vivo, bone marrow and periosteum are both involved in skeletal development, remodelling, and repair. In vitro, cell preparations derived from these two tissues have been shown to contain osteogenic and chondrogenic potential. Despite these in vivo and in vitro similarities, both cell populations are intrinsically different. Colnot (2009) assessed the cellular contributions of bone marrow and periosteum to bone healing in vivo. Based on the distinct contribution of cells from the periosteum and bone marrow during bone repair, they concluded that the populations of progenitor cells within both tissues varied. 
The same conclusion was drawn by Solchaga et al. (1998), who reported that bone marrow derived MSCs and periosteum-derived cells responded differently to osteoinductive agents in vitro. Due to these intrinsic differences between human bone marrow derived MSCs and hPDCs, fibrin sealant might influence the osteogenic differentiation of both cell populations differently. This again indicates that great caution should be taken when translating findings between osteogenic cell populations.

\section{Additional References}

Colnot C (2009) Skeletal fate decisions within periosteum and bone marrow during bone regeneration. $\mathrm{J}$ Bone Miner Res 24: 274-282.

Solchaga LA, Cassiède P, Caplan AI (1998) Different response to osteo-inductive agents in bone marrow and periosteum-derived cell preparations. Acta Orthop Scand 69: $426-432$. 